\title{
CROSS-BREEDING OF DISTILLERS' YEAST BY HYBRIDIZATION OF SPORE DERIVED CLONES
}

\author{
by \\ BJØRN EGGERT CHRISTENSEN
}

\author{
Danish Distillers Ltd., Raffinaderivej 10, \\ DK-2300 Copenhagen S \\ and
}

Department of Physiology, Carlsberg Laboratory, Gamle Carlsberg Vej 10, DK-2500 Copenhagen Valby

\begin{abstract}
Keywords: Saccharomyces cerevisiae, sporulation, hybridization, selection, fermentation, ethanol tolerance
\end{abstract}

\begin{abstract}
Four distillers' yeasts, strains A, B, C and D yielded 1-, 2-, 3- and 4-spored asci upon sporulation. Isolated $a$ and $\alpha$ mater strains, recovered from 4-spored asci by microdissection, were intercrossed to produce a total of 425 hybrids. The meiotic segregants and hybrids were tested for fermentation kinetics in a synthetic sucrose medium using a small scale batch system. A few hybrids exceeded the performance of the parent strains with respect to fermentation rate and final degree of fermentation.

A population derived from random mass mating of spores was subjected to selection for ethanol tolerance by repeated fermentations. Among a total of 56 clones tested most gave the same or a higher final ethanol concentration than the reference strain also when the fermentation rate was lower.
\end{abstract}

\section{INTRODUCTION}

The distilling industry requires fast fermenting ethanol tolerant yeasts which possess the ability to produce high concentrations of ethanol while remaining viable. A range of genetic and physiological factors affect the fermentation performance of yeasts.

The response of yeast cells to ethanol is complex and has been shown to be strain dependant and affected by many genes $(10,15,16,17$, 32). Hybridization and selection are considered important tools for the improvement of yeast strains in the brewing $(11,17,33)$, baking $(4,12$, $34,35)$ and winemaking $(10,29,32)$ industries. Mutagenesis has been used in the breeding of ethanol tolerant wine yeasts (1) and selective hybridization has produced hybrids with a better wine making potential $(10,32)$. Ethanol resistant variants have been recovered by selection in batch $(8)$ as well as continuous cultures $(3,21)$ and protoplast fusion has been used to create strains with improved fermentation characteristics $(22,27)$.

In addition to the genome, the environment is important for ethanol tolerance and fermentation performance $(6,18)$. Osmotic pressure $(25)$, the presence of unsaturated fatty acids and sterols $(2,5,19,30,31)$ and temperature $(13,14$, $18,23,24)$ influence the effect of ethanol on yeast cells.

Inheritance of the fermentation ability and tolerance to ethanol formed during the fermen-

Abbreviations: YPD = yeast extract, peptone, dextrose. 
Table I. Principal strain used.

\begin{tabular}{|c|c|c|}
\hline Strain & Genotype & Source \\
\hline A & & Production strain DDSF 102*) \\
\hline B & & Production strain DDSF $3^{\circ}$ ) \\
\hline $\mathrm{C}$ & & Production strain DDSF $6^{*}$ ) \\
\hline $\mathrm{D}$ & & Production strain DDSF $72^{*}$ ) \\
\hline D286-2a & a adel his 1 & $\begin{array}{l}\text { Course manual on yeast genetics, } \\
\text { Cold Spring Harbor Laboratory ( } 28 \text { ) }\end{array}$ \\
\hline D273-1 1a & $\alpha$ ade 1 his 1 & $\begin{array}{l}\text { Course manual on yeast genetics, } \\
\text { Cold Spring Harbor Laboratory ( } 28)\end{array}$ \\
\hline $\mathrm{AD}_{236}$ & & $A_{79} \times D_{64}$ \\
\hline $\mathbf{M}_{236}$ & & $\begin{array}{l}\text { Population derived from random } \\
\text { mass mating of spores from } A D_{236}\end{array}$ \\
\hline
\end{tabular}

"The production strains are from the Danish Distillers Ltd. Culture Collection.

tation were in the present work studied in production strains, meiotic segregants and hybrids. Small scale batch fermentations using a synthetic sucrose medium were used in the evaluation of fermentation performance as this method is simple and reliable and thus useful when large numbers of yeast strains are to be tested.

\section{MATERIALS AND METHODS}

\subsection{Strains and media}

The principal strains of Saccharomyces cerevisiae used in this study are listed in Table I. Strain $\mathrm{A}$ is a production strain used both as a distillers' yeast and for the manufacture of bakers' yeast strains.

The following media were employed (28): YPD contained 1\% Difco Bacto Yeast Extract, 2\% Difco Bacto Peptone, 2\% Dextrose. Presporulation medium was $0.8 \%$ Difco Bacto Yeast Extract, 0.3\% Difco Bacto Peptone, 10\% glucose ( $\mathrm{pH} 5.0$ ). Sporulation medium was $1 \%$ potassium acetate, $0.1 \%$ Difco Bacto Yeast Extract, $0.05 \%$ glucose. The synthetic fermentation medium consisted of $30 \%$ sucrose, $0.67 \%$ Difco Yeast Nitrogen Base without amino acids, and was buffered with $1 \%$ succinic acid and $0.6 \%$ sodium hydroxide. Plates were solidified with 2\% Difco Bacto Agar.

\subsection{Sporulation and spore recovery}

After two days of growth on a pre-sporulation plate, yeast cells were transferred to a sporulation plate and incubated 3-5 days at $30{ }^{\circ} \mathrm{C}$. Sporulation was detected by staining with malachite green - safranine (26). Clones from single spores were obtained by microdissection (28).

Isolation of random spores proceeded as described by GJERMANSEN and SigSGaARD (11), except for the ascus opening and the killing of the vegetative cells, where the procedure described by CHRISTENSEN (7) was used.

\subsection{Determination of mating type}

After 2 days at $30^{\circ} \mathrm{C}$ on YPD plates spore colonies were transferred to sporulation medium and tested for sporulation as described in 2.2. Non-sporulating colonies were considered to be potential mater strains. Mating ability was determined by mixing, on YPD plates, with the $\alpha$ tester strain (D273-1 1a) and the a tester strain (D286-2a). After 2 days the cell mass was replica plated onto sporulation medium; subsequent sporulation after 2-3 days on sporulation medium was taken as an indication of mating. A colony was designed mating type a when sporulation occurred after mixing with the $\alpha$ tester and as mating type $\alpha$ when sporulation took place after mixing with the a tester. For practical purposes, the colonies which would not sporu- 
late after mixing with either of the tester strains were classified as non-maters.

\subsection{Construction of hybrids}

The isolated strains of opposite mating type were crossed pairwise by mixing them on a YPD plate and incubating them at $30^{\circ} \mathrm{C}$ for 24 hours. Subsequently, the mixture was streaked on YPD plates for single colonies and the larger single colonies were isolated and checked for sporulation.

\subsection{Test fermentation and analysis of the fermented substrate}

Hybrids were propagated by inoculating cell material from a distinct colony into $10 \mathrm{ml} \mathrm{YPD}$ in test tubes followed by aerobic incubation at 30 ${ }^{\circ} \mathrm{C}$ for 20 hours. Approximately $1 \cdot 10^{8}$ cells from this culture were transferred to $250 \mathrm{ml}$, YPD at $30{ }^{\circ} \mathrm{C}$ and allowed to grow aerobically at $30^{\circ} \mathrm{C}$ for 20 hours. The cell density was then approximately $1 \cdot 10^{8}$ cells $\cdot \mathrm{ml}^{-1}$. The yeast cells were harvested by centrifugation and washed with sterile cold distilled water. Approximately $5 \cdot 10^{9}$ cells were suspended in $10 \mathrm{ml}$ fermentation medium in $250 \mathrm{ml}$ conical flasks stoppered with fermentation locks filled with concentrated sulphuric acid. The fermentation was allowed to take place with agitation for 44 hours at $30^{\circ} \mathrm{C}$ interrupted by weight determinations at $0,2,4$, $8,20,22,24,27$ and 44 hours. The decrease in weight measures the $\mathrm{CO}_{2}$ loss from the system, a loss which is proportional to the ethanol produced and the reduction in sucrose. A weight loss of $1.00 \mathrm{~g}$ corresponds to the formation of $1.05 \mathrm{~g}$ ethanol. The final ethanol concentration was determined either by the oxidative method (9) or alternatively by HPLC in a BIO-RAD Ion Exclusion Column $(250 \times 4 \mathrm{~mm})$ packed with Aminex HPX-85.

The fermentation rate was determined as the mean decrease in weight per hour between 4 and 8 hours of fermentation. Samples for determination of cell number and viability during the fermentation were achieved through teflon tubing (internal diameter $1 \mathrm{~mm}$ ) inserted in the fermentation lock to minimize the introduction of oxygen. The optical density at $660 \mathrm{~nm}\left(\mathrm{OD}_{660}\right)$ was determined prior to and after fermentation. The number of cells in suspension was determined by a haemocytometer or with a Coulter Counter model ZB. The viability of the yeast was determined by plating appropriate dilutions of the fermentation mixture onto YPD plates and counting the number of colonies. Each hybrid was fermented in a minimum of two parallel flasks and two independent reference fermentations (each consisting of 2 parallel flasks) with strain A were included in every fermentation "run".

\section{RESULTS}

\subsection{Sporulation, spore recovery and construction of hybrids}

Strains A, B, C and D sporulated well; the sporulation frequencies after 3-5 days on sporulation medium ranged from $25-70 \%$, being $70 \%$ for strain A. The percentage of 1-, 2-, 3- and 4-spored asci differed among the strains; strain A yielded $40 \% 4$-spored asci. Single spores were obtained from 4-spored asci by microdissection. Germination of the spores gave rise to clones of various morphologies. The frequency of asci giving complete tetrads with four viable spores was low, in the order of $0-10 \%$ for the four strains.

The germinated spores were characterized by their ability to sporulate and mate. From a total of 391 dissected 4-spored asci, $37 \alpha$ and 153 a clones were obtained. All maters were prototrophs and grew markedly slower than their parents. The non-maters comprised sporulating as well as non-sporulating segregants. The sporulation capability of some of the spores is due to polyploidy/aneuploidy and to the presence of genes for homothallism (20). A limited number of the sporulating clones were microdissected, but none of the spores germinated.

Hybrids were obtained by crossing clones of opposite mating type. A total of 425 hybrids were constructed which had sporulation ability. Sporulation was not observed in all combinations of $\mathbf{a}$ and $\alpha$ maters. It was not investigated whether this was due to inefficient mating or to lack of sporulation in the hybrids. 


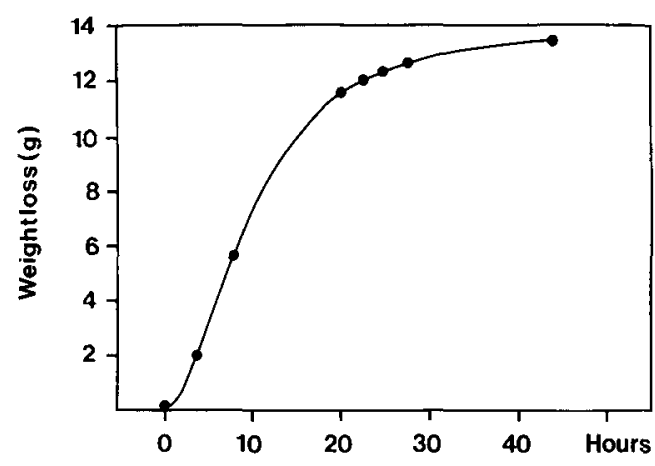

Figure 1. Fermentation curve for strain A. Mean weight losses from a single experiment with 2 parallel cultures are plotted against time. The deviation of the plotted independent values is less than $2 \%$.

\subsection{Fermentation tests of meiotic segregants and hybrids}

The typical progress of a batch fermentation is shown in Figure 1. The yeast strain $\mathrm{A}$ was inoculated into $100 \mathrm{ml}$ sucrose medium at $30^{\circ} \mathrm{C}$ and the decrease in weight was followed. The maximum fermentation rate was reached between 4 and 8 hours; the weight loss at 20 hours and after 44 hours (final weight loss) were chosen as simple parameters to assess fermentation ability. The deviation between the values of the two independent strain A cultures in each "run" is typically less than $2 \%$ as are the weight losses from the two parallel fermentation flasks containing the yeast under test. However, in repeated experiments the values for strain A can differ by up to $\pm 15 \%$. Figures 2,3 and 4 give the frequency distribution of fermentation rates, 20 hour weight loss and final weight loss for a number of experiments in duplicate with the reference strain $A$, experiments with meiotic segregants derived from strain $\mathrm{A}$ and hybrids constructed from some of the meiotic segregants. The distribution for strain A shows the intrinsic variation of the fermentation system used. A significantly wider range of values was found for the meiotic segregants reflecting the segregation of genes affecting fermentation rate, ethanol tolerance and other relevant parameters. Hybrids made from meiotic segregants of strain A display a wider variation than the
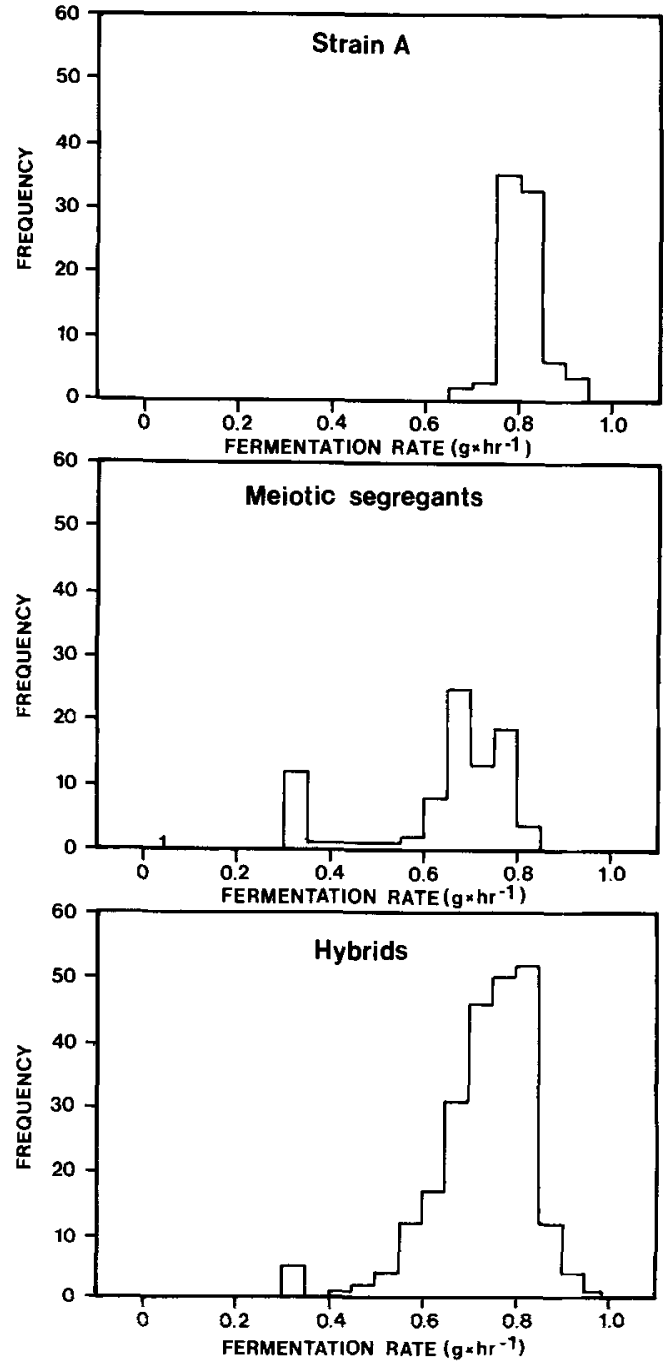

Figure 2. Frequency distributions of fermentation rate for 91 experiments with strain $A$, for 87 experiments with meiotic segregants derived from strain $A$ and for 246 hybrids constructed from some of these meiotic segregants. The distributions for strain $\dot{A}$ show the variation occurring with the fermentation system employed. The additional variance found in the population of meiotic segregants, and in the hybrids, reflects the segregation of genes affecting the fermentation rate.

original strain, but the frequency distributions are less spread than those recorded for the meiotic segregants. None of the meiotic segregants attained a performance equal to strain $\mathrm{A}$ whereas some of the hybrids did. 

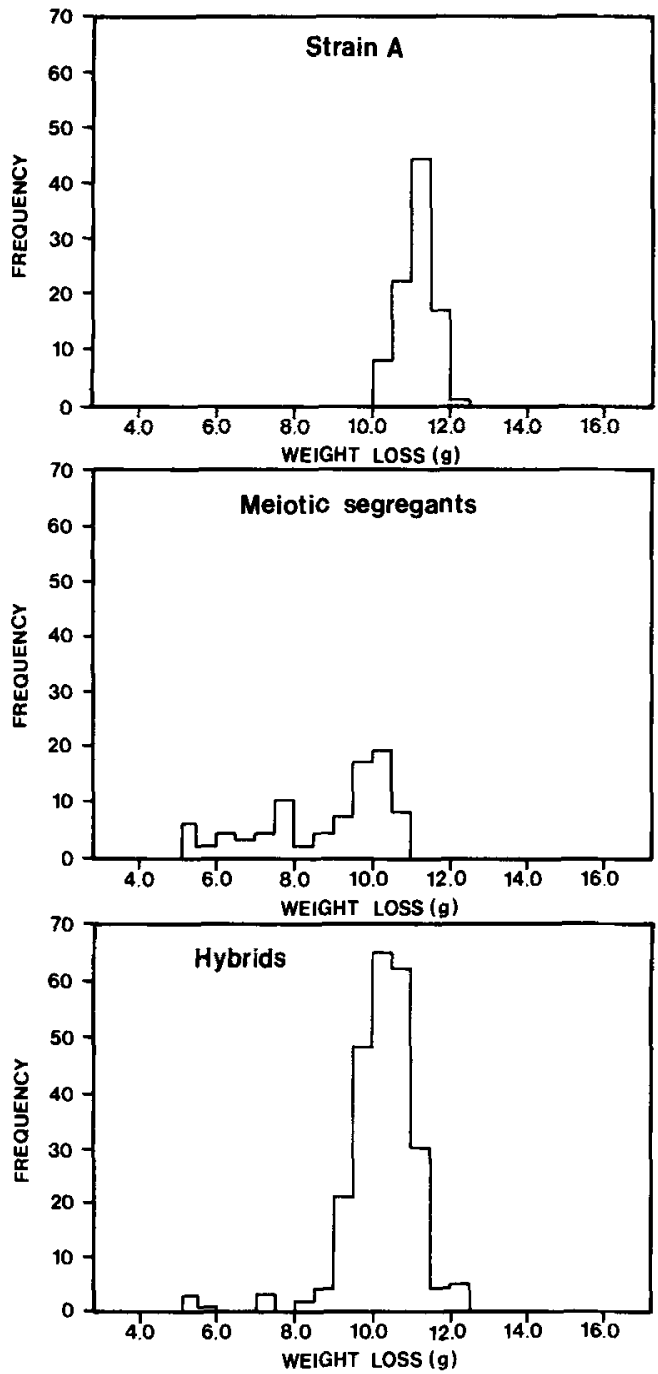

Figure 3. Frequency distributions of 20 hour weight losses for 86 experiments with strain A, for 85 fermentations with meiotic segregants derived from strain $A$ and for 246 hybrids constructed from some of these meiotic segregants.

Cell viability was fairly constant for the first 20 hours of the fermentation, but decreased drastically as ethanol concentration reached its maximum value of $12-13 \%(\mathrm{w} / \mathrm{v})$. Biomass doubled during the first part of the fermentation but decreased at 44 hours because of autolysis.

Among the 425 tested hybrids, 13 had both a higher rate of fermentation and reached a higher final ethanol concentration than the reference
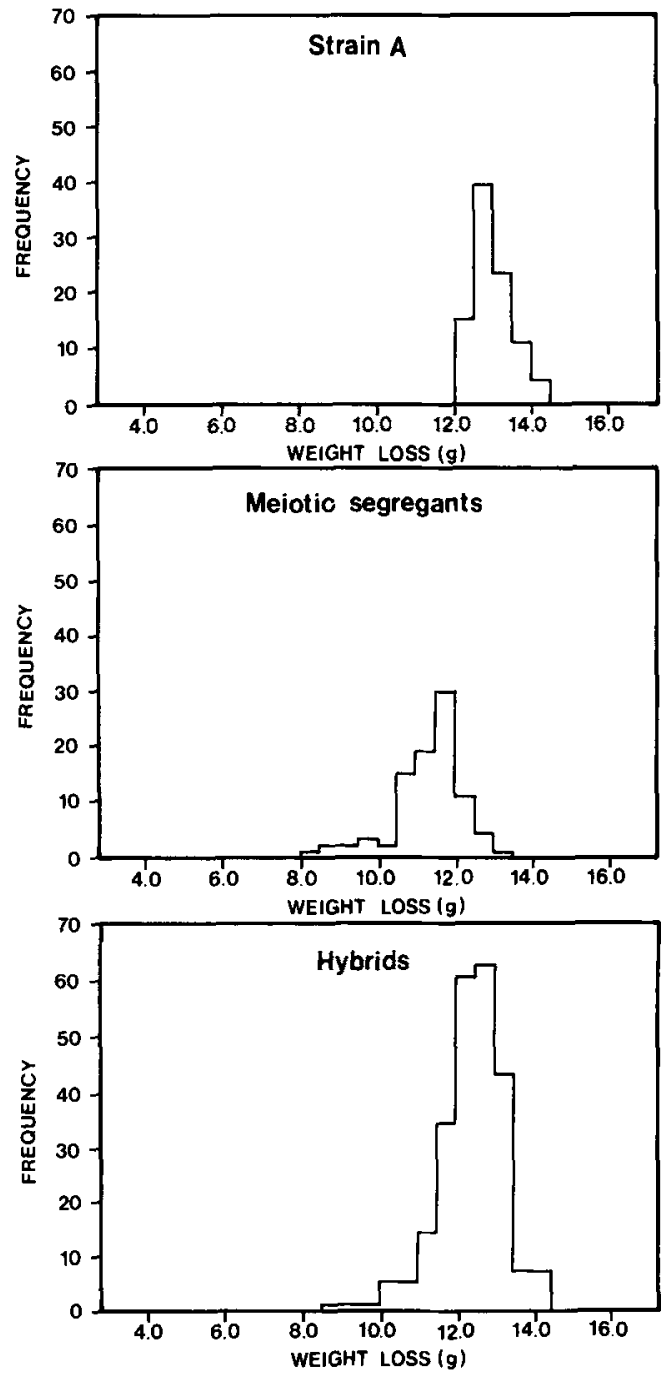

Figure 4. Frequency distributions of the final weight losses for 86 experiments with strain A, 85 experiments with meiotic segregants derived from strain $A$ and 244 hybrids constructed from some of these meiotic segregants.

strain. Table II shows the fermentation data both for these hybrids and their parental lines, i.e., the meiotic segregants from which they are constructed. With the exception of a few values of the meiotic segregants $A_{6}, A_{209}, A_{283}$ and $A_{317}$ strain A scored higher than the parental lines, which generally attain only mediocre values in the fermentations. Note that the meiotic segregant $A_{370}$ is the $\alpha$ parent of 9 of the selected 13 
Table II. Fermentation parameters for meiotic segregants from strain $\mathbf{A}$ hybrids with fermentation parameters as good as or better than those of the reference strain $A$. These are compared with the results from their parental lines and parallel fermentations with the original strain $A$. Fermentation rate is calculated as the mean weight loss per hour between 4 and 8 hours after the onset of fermentation. The theoretical maximum weight loss is $15.44 \mathrm{~g}$.

\begin{tabular}{|c|c|c|c|c|c|}
\hline & \multirow[t]{2}{*}{ Strain } & & \multirow{2}{*}{$\begin{array}{l}\text { Fermentation } \\
\text { rate }\left(\mathrm{g} \cdot \mathrm{hr}^{-1}\right)\end{array}$} & \multicolumn{2}{|c|}{ Weight loss $(\mathrm{g})$} \\
\hline & & & & 20 hours & final \\
\hline & Hybrids: & Cross of & & & \\
\hline & & a $\quad a$ & & & \\
\hline \multirow[t]{2}{*}{ 1) } & $\mathrm{AA}_{70}$ & $\mathrm{~A}_{209} \times \mathrm{A}_{\mathbf{8 7}}$ & 0.81 & 10.9 & 14.2 \\
\hline & A & & 0.77 & 10.5 & 12.8 \\
\hline \multirow[t]{2}{*}{ 2) } & $\mathrm{AA}_{348}$ & $A_{374} \times A_{370}$ & 0.92 & 12.0 & 14.0 \\
\hline & A & & 0.88 & 11.5 & 13.3 \\
\hline \multirow[t]{2}{*}{ 3) } & $\mathrm{AA}_{442}$ & $A_{235} \times A_{370}$ & 0.89 & 11.5 & 13.0 \\
\hline & A & & 0.87 & 11.2 & 12.8 \\
\hline 4) & $\mathrm{AA}_{452}$ & $\mathbf{A}_{283} \times \mathbf{A}_{370}$ & 0.84 & 11.5 & 13.0 \\
\hline 5) & $\mathrm{AA}_{458}$ & $\mathrm{~A}_{314} \times \mathrm{A}_{370}$ & 0.85 & 12.0 & 13.7 \\
\hline \multirow[t]{2}{*}{ 6) } & $\mathrm{AA}_{459}$ & $\mathrm{~A}_{317} \times \mathrm{A}_{370}$ & 0.89 & 12.3 & 14.4 \\
\hline & A & & 0.83 & 11.4 & 13.0 \\
\hline 7) & $\mathrm{AA}_{466}$ & $A_{341} \times A_{370}$ & 0.91 & 11.6 & 13.4 \\
\hline 8) & $\mathrm{AA}_{46 ?}$ & $\mathrm{~A}_{342} \times \mathrm{A}_{370}$ & 0.95 & 12.4 & 14.3 \\
\hline 9) & $\mathrm{AC}_{476}$ & $\mathrm{C}_{417} \times \mathrm{A}_{370}$ & 0.89 & 11.4 & 13.4 \\
\hline \multirow[t]{2}{*}{ 10) } & $\mathrm{AC}_{481}$ & $\mathrm{C}_{473} \times \mathrm{A}_{370}$ & 0.89 & 11.6 & 13.7 \\
\hline & A & & 0.89 & 11.3 & 12.9 \\
\hline \multirow[t]{2}{*}{ 11) } & $\mathrm{AC}_{327}$ & $\mathrm{~A}_{6} \times \mathrm{C}_{412}$ & 0.83 & 11.3 & 14.0 \\
\hline & A & & 0.81 & 10.9 & 12.8 \\
\hline 12) & $\mathrm{AD}_{233}$ & $A_{6} \times D_{64}$ & 0.91 & 12.7 & 13.1 \\
\hline \multirow[t]{2}{*}{ 13) } & $\mathrm{AD}_{234}$ & $\mathrm{~A}_{16} \times \mathrm{D}_{64}$ & 0.86 & 12.2 & 13.2 \\
\hline & A & & 0.82 & 11.2 & 12.8 \\
\hline \multicolumn{6}{|c|}{ Parental lines (meiotic segregants of A): } \\
\hline & & \multicolumn{4}{|c|}{ Parent to hybrid: } \\
\hline & $A_{6}(\mathbf{a})$ & 11) 12) & 0.76 & 11.0 & 13.2 \\
\hline & $A_{16}(a)$ & 13) & 0.69 & 9.0 & 11.1 \\
\hline & A & & 0.87 & 10.9 & 12.7 \\
\hline & $D_{64}(\boldsymbol{\alpha})$ & 12) 13) & 0.80 & 9.8 & 10.3 \\
\hline & $A_{87}(\alpha)$ & 1) & 0.43 & 6.3 & 8.0 \\
\hline & $A_{370}(\alpha)$ & 2)-10) & 0.80 & 10.5 & 11.3 \\
\hline & $\mathrm{C}_{412}(\alpha)$ & 11) & 0.45 & 7.7 & 11.4 \\
\hline & A & & 0.90 & 11.3 & 12.4 \\
\hline & $A_{209}$ (a) & 1) & 0.74 & 10.8 & 12.6 \\
\hline & A & & 0.81 & 11.1 & 12.4 \\
\hline & $A_{235}(\mathbf{a})$ & 3) & 0.78 & 10.2 & 11.9 \\
\hline & $\mathrm{A}_{283}$ (a) & 4) & 0.77 & 10.5 & 12.3 \\
\hline & A & & 0.83 & 10.9 & 12.1 \\
\hline & $\mathrm{A}_{314}(\mathbf{a})$ & 5) & 0.71 & 9.6 & 11.5 \\
\hline & $\mathrm{A}_{317}$ (a) & 6) & 0.35 & 8.6 & 12.3 \\
\hline & $A_{341}(a)$ & 7) & 0.70 & 9.9 & 11.9 \\
\hline & $\mathrm{A}_{342}(\mathrm{a})$ & 8) & 0.22 & 4.4 & 8.7 \\
\hline & A & & 0.81 & 10.8 & 12.1 \\
\hline & $\mathrm{A}_{374}(\mathbf{a})$ & 2) & 0.69 & 9.4 & 10.8 \\
\hline & A & & 0.90 & 11.4 & 12.6 \\
\hline & $\mathrm{C}_{417}$ (a) & 9) & 0.84 & 10.8 & 12.0 \\
\hline & $\mathrm{C}_{473}$ (a) & 10) & 0.83 & 10.6 & 11.9 \\
\hline & A & & 0.88 & 11.6 & 12.6 \\
\hline
\end{tabular}


Table III. Rate of survival of the population $\mathbf{M}_{236}$ after repeated fermentations selecting for increased ethanol tolerance.

\begin{tabular}{lccccc}
\hline \multirow{2}{*}{ Strain } & $\mathrm{AD}_{236}$ & \multicolumn{3}{c}{$\mathrm{M}_{236}$} \\
\cline { 3 - 5 } & & 1. trial & 3. trial & 4. trial \\
\hline Survival (\%) & 0.00004 & 0.07 & 2 & 35 \\
\hline
\end{tabular}

hybrid strains. The line $\mathrm{A}_{370}$ turned out to be one of the few $\alpha$ strains able to form hybrids with the majority of the a mating type meiotic segregants.

\subsection{Selection on a genetically heterogeneous population}

In the experiments described above the number of hybrids which could be screened was limited by the fact that they were isolated individually. It was therefore decided to set up a selection experiment among a large number of genetically different hybrids.

The hybrid $\mathrm{AD}_{236}$ was sporulated and a suspension of spores was prepared and allowed to germinate for two days thus forming a population of meiotic segregants and hybrids, $\mathbf{M}_{236}$. After propagation the population was subjected to fermentation conditions at $30^{\circ} \mathrm{C}$ for approximately 50 hours under conditions as described in 2.5. One $\mathrm{ml}$ of the fermentation mixture was plated on YPD and after two days live cells were recovered, propagated and fermented anew thus selecting for cells able to tolerate high ethanol concentrations. The procedure was repeated 4 times.

Table III gives the changes in viability of the populations. The survival rate of $\mathbf{M}_{236}$ cells was raised 5 orders of magnitude as compared to $\mathrm{AD}_{236}$. The biomass, measured as $\mathrm{OD}_{660}$, increased 2-3 times during all four fermentations as did the total cell number. Both values dropped slightly at the end of the fermentation.

Fifty six strains were isolated as single colonies from the population after 4 selective fermentations and tried in small scale batch fermentations. All isolates had a significantly lower fermentation rate and a lower weight loss than the reference strain at 20 hours, whereas the final weight loss in all strains was equal to or exceed-
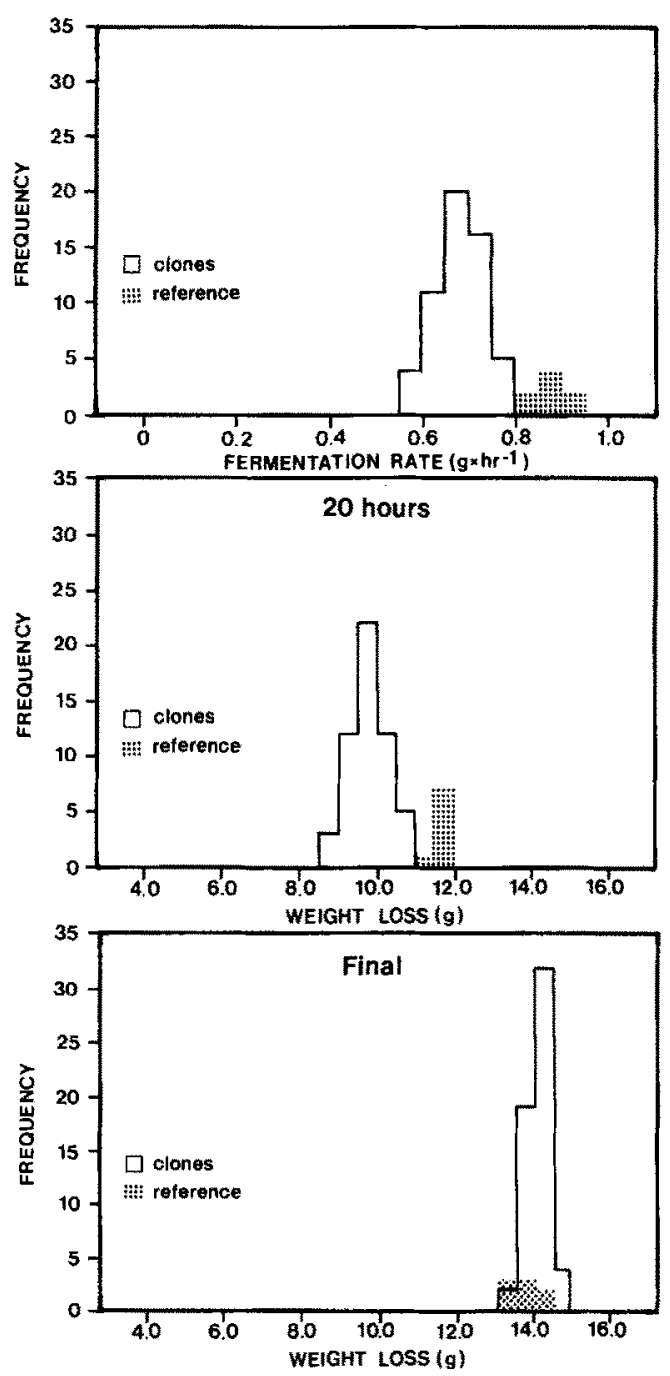

Figure 5. Frequency distributions of fermentation rate and weight losses at 20 and 44 hours for 56 ethanol tolerant clones selected from a population, $\mathbf{M}_{236}$. The distributions are compared to 8 independent fermentations with strain A. Fermentation rate and weight losses at 20 hours are significantly lower for the clones than strain $\mathrm{A}$. This is in contrast to the final weight loss where a few ethanol tolerant strains exceed strain A. 
ing that of strain A. Figure 5 presents the frequency distributions for fermentation rate and weight loss among the 56 isolates and strain A. The viability of the isolates from the population ranged from $1 \%$ to $20 \%\left(10^{7}-10^{8}\right.$ cells $\left.\cdot \mathrm{ml}^{-1}\right)$.

\section{DISCUSSION}

Among the meiotic segregants of the strains A, $B, C$ and $D$ some have mating type $\mathbf{a}$, some $\alpha$ and others are able to sporulate. Similar results have been obtained with brewers' yeast (11) and osmotolerant bakers' yeasts (12).

By tetrad analysis of restriction endonuclease fragment polymorphisms, KEIDING (20) has shown that spore clones of strain A were disomic for at least 7 chromosomes, and that four different chromosomes III are present in the strain. Of the four chromosomes III, three were lacking HML and one HMR. These results indicate that strain $A$ is tetraploid and heterozygous for a number of tested chromosome regions (20). The acquired detailed genetic knowledge about strain $\mathrm{A}$ as well as the finding that it contains $\mathrm{HO}$, a gene for homothallism, can now be taken into account in efforts to improve the performance of this strain by using its inherent genetic variation in breeding.

One hundred and twenty seven meiotic segregants and 425 hybrids were tested for fermentation ability. They showed very wide ranges of fermentation rate as well as degree of fermentation at specified times. Only 13 hybrids performed equal to or slightly better than the reference strain. The meiotic segregants and hybrids varied because of the meiotic segregation of genes controlling the fermentation process. These results are similar to the findings on the selective hybridization of wine yeasts; hybrids and meiotic segregants differed in their potential to give high ethanol yields and a few of the isolated hybrids compared favourably with commercial wine yeast strains $(10,32)$.

KORHOLA (21) and Brown and Oliver (3) obtained ethanol tolerant yeasts by selection in continious cultures. Stable ethanol tolerant strains were produced by the addition of ethanol to the fermenting cultures under controlled feed-back conditions. The resulting strains gave higher rates of fermentation and ethanol con- centrations than their parent strains. Somewhat different results were obtained in the present work where selection for ethanol tolerance was achieved by repeatedly subjecting a population derived from strain $\mathrm{AD}_{236}$ by mass spore isolation followed by random mass mating. Single cell isolates recovered from this population did not exhibit great fermentation vigour, but did show increased viability and increased ability to reach high ethanol concentrations.

The screening and selection schemes described here were designed for batch fermentations where the yeast cells were subjected to substrate inhibition followed by ethanol inhibition as opposed to continuous systems where the formed ethanol acts as the main selective factor.

Screening for yeasts with a high fermentation rate and yielding a high final ethanol concentration gave only a few hybrids better than the reference strain. However, the approach is promising as it has demonstrated considerable genetic variation among the strains. Meiotic segregants have been obtained, and these have by mating yielded hybrids with a fermentation performance equal to or better than strains used in the alcohol production today. The fact opens the way for rational mutation breeding and for the introduction by genetic transformation of recessive markers and alleles considered important in breeding.

\section{ACKNOWLEDGEMENTS}

The encouragement by and helpful discussions with Diter von WetTSTEIN, MORTEN KIELLAND-BRANDT and KNUT ROSÉN are greatly appreciated. I wish to thank ANNE SAHLGREN and JOYCELYN ENTWISTLE for outstanding technical assistance, and BJARNE ADAMSEN, INGE Hallas, BirgitTe JørGENSEN and INGRID THOMAS for performing the HPLC analyses of the fermented medium.

\section{REFERENCES}

1. Alikhanyan, S. I. \& G. M. Nalbandyan: Selection of wine yeast using mutagens. Soviet Genetics 2, 1200-1205 (1971)

2. Beaven, M. J., C. Charpentier \& A. H. Rose: Production and tolerance to ethanol in relation to 
phospholipid fatty-acyl composition in Saccharomyces cerevisiae NCYC 431. J. Gen. Microbiol. $128,1447-1455$ (1982)

3. BROWN, S. W. \& S. G. OLIVER: Isolation of ethanoltolerant mutants of yeast by continuous selection. Eur. J. Microbiol. Biotechn. 16, 119-122 (1982)

4. Burrows, S.: Bakers yeast. In: Economic Microbiology, A. H. Rose (ed. ), vol 4, Academic Press London New York, p. 32-64 (1979)

5. CASEY, G. P. \& W. M. Ingledew: Reevaluation of alcohol synthesis and tolerance in brewer's yeast. J. Am. Soc. Brew. Chem. 43, 75-83 (1985)

6. CASEY, G. P. \& W. M. INGLEDEW: Ethanol tolerance in yeasts. In: Critical Reviews in Microbiology, G. G. Stewart, I. Russell (eds. ), CRC Press, Boca Raton 13, 219-280 (1986)

7. Christensen, B. E.: Somatic hybridization in Saccharomyces cerevisiae: analysis of products of protoplast fusion. Carlsberg Res. Commun 44, 225-233 (1979)

8. Christensen, B. E.: Breeding for ethanol-tolerant distillers yeasts. In: Biological Research on Industrial Yeasts. G. G. Stewart, I. Russell, R. D. Klein, R. R. Heibsch (eds. ). Uniscience series, CRC Press, Boca Raton (1987)

9. Christensen, B. E. \& H. ERIKSEn: Screening and testing new distillers yeasts for their potential in molasses ethanol fermentations. In: Modern Methods of Plant Analysis. New Series, vol. 7, H. F. Linskens \& J. F. Jackson (eds. ) Springer (in press)

10. Eschenbruch, R.. K. J. Cresswell, B. M. Fischer \& R. J. THORNTON: Selective hybridization of pure culture wine yeasts. 1. Elimination of undesirable wine-making properties. Eur. J. Appl. Microbiol. Biotech. 14, 155-158 (1982)

11. GJermansen, C. \& P. SigsgaArd: Construction of a hybrid brewing yeast. Carlsberg Res. Commun. 46, 1-11 (1981)

12. GUNGE. N.: Breeding of Bakers yeast - Determination of the ploidy and an attempt to improve practical properties. Jap. J. Genet. 41, 203-241 (1966)

13. HaCking, A. J. I. W. F. TAYLOR \& C. M. Hanas: Selection of yeast able to produce ethanol from glucose at $40^{\circ} \mathrm{C}$. Appl. Microbiol. Biotechnol. 19, 361-365 (1984)

14. HolcberG. I. B. \& P. Margalith: Alcoholic fermentation by immobilized yeast at high sugar concentrations. Eur. J. Appl. Microbiol. Biotechnol. 13, 133-140 (1981)

15. Ismail, A. A. \& A. A. M. Ali: Selection of high ethanol yielding Saccharomyces. 1. Ethanol tolerance and the effect of training in Saccharomyces cerecisiae. Folia Microbiol. 16, 346-349 (1971a)
16. IsmaIL. A. A. \& A. A. M. All: Selection of high ethanol yielding Saccharomyces. II. Genetics of ethanol tolerance. Folia Microbiol. 16, 350-354 (1971b)

17. Johnston, J. R.: Breeding yeasts for brewing. II. Production of hybrid strains. J. Inst. Brew. 71, 135-137 (1965)

18. Jones. R. P.. N. Pamment \& P. F. Greenfield: Alcohol fermentations by yeasts; the effect of environmental and other variables. Process Biochem. 16, 42-49 (1981)

19. KALMOKOFF, M. \& W. M. INGLEDEW: Evaluation of ethanol tolerance in related Saccharomyces strains. J. Am. Soc. Brew. Chem. 43(4), 189-196 (1985)

20. KEIDING, A. K.: Genetic and molecular characterisation of a distiller's yeasts. Carlsberg Res. Commun. 50, 95-125 (1985)

21. KORHOLA, M.: Improvement of yeast strains for added ethanol tolerance. In: Gene Expression in Yeast. M. Korhola, E. Vaisanen eds. Proceedings of the Alco Yeast Symposium. Helsinki pp. 231242 (1983)

22. LegmanN. R.\& P. MARGalith: Ethanol formation by hybrid yeasts. Appl. Microbiol. Biotechnol. 23, 198-202 (1986)

23. Nagodawithana, T. W.. C. Castellano \& K. H. StEINKRAUS: Effect of dissolved oxygen, temperature, initial cell count and sugar concentration on the viability of Saccharomyces cerevisiae in rapid fermentations. Appl. Microbiol. 28, 383-39l (1974)

24. NagodaWithana, T. W.\& K. H.STEInKRaUS: Influence of the rate of ethanol production and accumulation on the viability of Saccharomyces cerevisiae in rapid fermentation. Appl. Environ. Microbiol. 31, 158-162 (1976)

25. Panchall, C. J. \& G. G. Stewart: The effect of osmotic pressure on the production and excretion of ethanol and glycerol by a brewing yeast strain. J. Inst. Brew. 86, 207-210 (1980)

26. SChaeffer. A. B. \& M. Fulton: A simplified method of staining endospores. Science 77, 194 (1933)

27. SeKi. T.. S. Myoga. S. Limtong, S. Vedono, J. KumNUANTA \& J. TAGUCHI: Genetic construction of yeast strains for high ethanol production. Biotechn. Letters 5, 351-356 (1983)

28. Sherman, F., G. R. Fink \& C. W. Lawrence: Course manual on yeast genetics. Cold Spring Harbor (1974)

29. SNOW, D.: Toward genetic improvement of wine yeast. Am. J. Enol. Vitic. 30(1), 33-37 (1979)

30. Thomas. D. S. J. A. HossaCK \& A. H. Rose: Plasma membrane lipid composition and ethanol toler- 
ance in Saccharomyces cerevisiae. Arch. Microbiol. 117, 239-245 (1978)

31. Thomas. D. S. \& A. H. Rose: Inhibitory effect on growth and solute accumulation by Saccharomyces cerevisiae as effected by plasma-membrane lipid composition. Arch. Microbiol. 22, 49-55 (1979)

32. Thornton, R. J.: Selective hybridization of pure culture wine yeasts II. Improvement of fermentation efficiency and inheritance of $\mathrm{SO}_{2}$ tolerance. Eur. J. Appl. Microbiol. Biotechnol. 14, 159-164 (1982)

Accepted by E. LuND
33. Wettstein, D. von.C. Gjermansen, S. Holmberg, M. C. Kielland-Brandt. T. Nilsson-Tillgren, M. B. Pedersen. J. G. Litske Petersen \& P. SigsGAARD: Genetic engineering in the improvement of brewers yeast. MBBA Tech. Q. 21, 45-61 (1984)

34. WINDISCH, S.: Erfahrungen auf dem Wege, neue Hefestämme für technishe Zwecke zu finden und zu züchten. Branntweinwirtschaft 123, 30-34 (1983)

35. Windisch, S.. S. Kowalsky \& I. Zander: Doughraising tests with hybrid yeasts. Eur. J. Appl. Microbiol. 3, 213-221 (1976) 